\title{
DIAGNÓSTICO DOS MUNICÍPIOS DE MATO GROSSO QUANTO A EXISTÊNCIA DE ATERROS SANITÁRIOS
}

Rafaela de Araújo Costa - rafaela_araujocosta@hotmail.com Universidade Federal de Mato grosso

Dempsey Thrweyce Alves da Silva - dempsey_alves@hotmail.com Universidade Federal de Mato grosso

Emanuelly Veronica Soares Leoncio - manuleoncio01@ hotmail.com

Universidade Federal de Mato Grosso

Ricardo de Sousa Carneiro - ricardo.carneiro.mt@gmail.com

Universidade Federal de Mato Grosso 


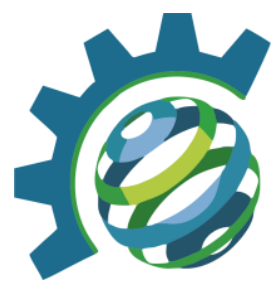

\section{RESUMO}

Aterro sanitário é um método de disposição de resíduos sólidos urbanos no solo que visa proteger o meio ambiente e a saúde pública favorecendo a segurança e o bem-estar da população. Em Mato Grosso, o licenciamento ambiental dos aterros sanitários é de responsabilidade da Secretaria de Estado do Meio Ambiente - SEMA/MT, e a aprovação do EIA/RIMA e realização de audiências públicas para tomadas de decisão é de responsabilidade do Conselho Estadual do Meio Ambiente - CONSEMA. O objetivo deste trabalho é apresentar um diagnóstico da situação dos municípios de Mato Grosso quanto à existência de aterros sanitários licenciados. Os dados obtidos sobre a realidade dos municípios foram compilados e divididos em cinco grupos, que vão desde o grupo de municípios que nunca iniciaram o processo de regularização até os municípios que possuem ou já possuíram Licença de Operação para seus aterros. Observou-se que 53,38\% do total de municípios nunca iniciaram o processo de regularização, e apenas 20 municípios no estado possuem ou possuíram aterros sanitários com Licença de Operação.

Palavras-chave: Diagnóstico, aterros sanitários, licenciamento.

\section{INTRODUÇÃO/OBJETIVO}

Qualquer atividade humana produz lixo. A disposição inadequada dos resíduos sólidos, os conhecidos lixões, configura um dos grandes problemas ambientais da atualidade. Além de poluir o solo, a água e o ar, também são capazes de oferecer abrigo para animais que veiculam doenças diversas. De acordo com Muños (2002), aterro sanitário refere-se a uma instalação previamente planejada para a posterior disposição de resíduos sólidos, visando a não causar danos nem perigo ao meio ambiente e a saúde pública.

No aterro sanitário ocorre o emprego de técnicas de engenharia e normas operacionais específicas para confinar esses resíduos na menor área possível, reduzindo ao mínimo o seu volume, cobrindo-os em seguida com uma camada de terra ou material inerte, tão frequente quanto se fizer necessário ou ao final de cada jornada de trabalho. É necessário prever a impermeabilização da base e das laterais, sistemas de drenagem de chorume para tratamento, remoção segura e queima dos gases produzidos.

A Lei $\mathrm{N}^{\mathrm{o}}$ 12.305, de 02 de Agosto de 2010, que institui a Política Nacional de Resíduos Sólidos, nos respectivos incisos do Art. $3^{\circ}$ define:

XVI - resíduos sólidos: material, substância, objeto ou bem descartado resultante de atividades humanas em sociedade, a cuja destinação final se procede, se propõe proceder ou se está obrigado a proceder, nos estados sólido ou semissólido, bem como gases contidos em recipientes e líquidos cujas particularidades tornem inviável o seu lançamento na rede pública de esgotos ou em corpos d'água, ou exijam para isso soluções técnica ou economicamente inviáveis em face da melhor tecnologia disponível;

XV - rejeitos: resíduos sólidos que, depois de esgotadas todas as possibilidades de tratamento e recuperação por processos tecnológicos disponíveis e economicamente viáveis, não apresentem outra possibilidade que não a disposição final ambientalmente adequada;

VIII - disposição final ambientalmente adequada: distribuição ordenada de rejeitos em aterros, observando normas operacionais específicas de modo a evitar danos ou riscos à saúde pública e à segurança e a minimizar os impactos ambientais adversos; 


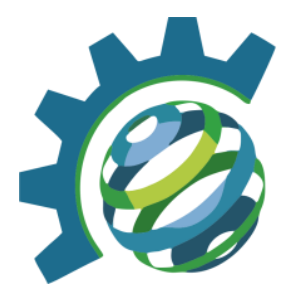

Em Mato Grosso, o licenciamento ambiental dos aterros sanitários, bem como a avaliação dos estudos e critérios ambientais para localização deste empreendimento é de responsabilidade da Secretaria de Estado do Meio Ambiente - SEMA/MT. A aprovação do EIA/RIMA e realização de audiências públicas para tomadas de decisão é de responsabilidade do Conselho Estadual do Meio Ambiente - CONSEMA. Este trabalho objetiva apresentar um diagnóstico dos municípios do estado de Mato Grosso quanto à existência de aterros sanitários e classifica-los em grupos de acordo com a disposição dos resíduos sólidos urbanos de cada município.

\section{METODOLOGIA}

O Estado de Mato Grosso possui posição estratégica e central na América do Sul, ocorrendo em seu território o divisor de águas das bacias dos rios Amazonas, TocantinsAraguaia e do Prata. A superfície é estimada em $903.357,908 \mathrm{~km}^{2}$ e possui uma população atual de 3.033,911 habitantes, segundo a estimativa populacional de $2010 \mathrm{com}$ dados coletados pelo IBGE. É o décimo nono estado mais populoso do Brasil, concentrando 1,47\% da população brasileira e ocupa a $9^{\circ}$ posição do IDH entre os estados brasileiros.

A grande maioria desta população está localizada na área urbana $(2.482 .801$ habitantes), enquanto apenas $20 \%$ da população está alocada na área rural $(552.321,00$ habitantes). Entretanto, este número de habitantes vem crescendo a uma taxa média de 1,62\% por ano, tendo passado de 1.597.009 habitantes em 1970 para o atual número de 3.035.122 habitantes em 2010, como pode ser observado na tabela que se segue.

Tabela 1 - População residente no período entre 1970-2010 e Taxa Média de Crescimento Anual (TMCA)

\begin{tabular}{ccccccc}
\hline \multirow{2}{*}{ Estado } & \multicolumn{5}{c}{ População Residente } & \multirow{2}{*}{ TMCA } \\
\cline { 2 - 6 } & 1970 & 1980 & 1991 & 2000 & 2010 & \\
\hline Mato Grosso & 1.597 .009 & 1.138 .918 & 2.027 .231 & 2.504 .353 & 3.035 .122 & $1,62 \%$ \\
\hline
\end{tabular}

Fonte: Modificado de IBGE (2010)

Para o diagnóstico da situação dos municípios de Mato Grosso quanto à existência de aterros sanitários licenciados a obtenção das informações foi realizada na SEMA/MT na Gerência de Resíduos Hospitalares e Urbanos da Coordenadoria de Gestão de Resíduos Sólidos.

Os dados obtidos sobre a realidade dos municípios foram compilados e divididos em cinco grupos:

- Grupo A: municípios que destinam os resíduos sólidos urbanos em lixões e nunca iniciaram o processo de regularização (municípios em inércia);

- Grupo B: municípios que destinam os resíduos sólidos em lixões e já realizaram estudo de alternativas locacionais para instalação de aterro sanitário;

- Grupo C: municípios que destinam os resíduos sólidos em lixões e já obtiveram Licença de Prévia para instalação de aterro sanitário;

- Grupo D: municípios que destinam os resíduos sólidos em lixões e já obtiveram Licença de Instalação para aterro sanitário; 

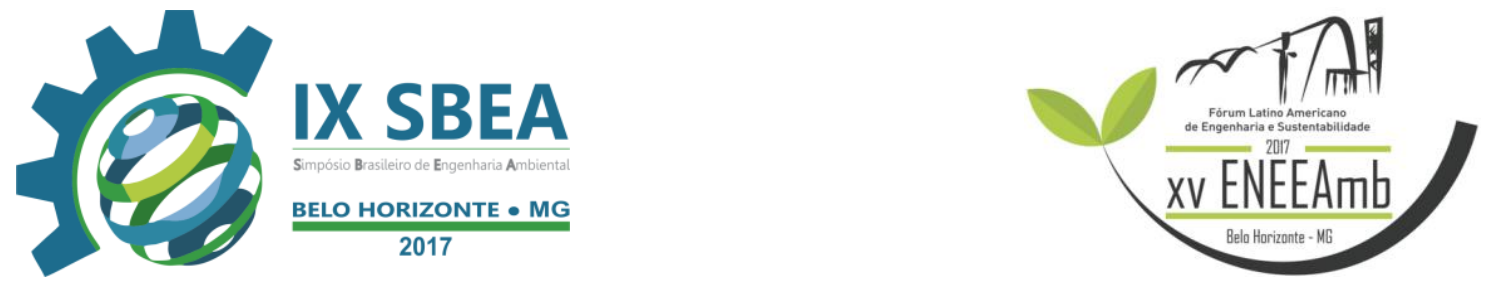

- Grupo E: municípios que destinam os resíduos sólidos urbanos em aterros que possuem ou já possuíram Licença de Operação;

\section{RESULTADOS E DISCUSSÃO}

\subsection{Análise global}

Dos 141 municípios do Estado, 53 encontram-se no Grupo A (municípios que destinam os resíduos sólidos urbanos em lixões e nunca iniciaram o processo de regularização), 32 no Grupo B (municípios que destinam os resíduos sólidos em lixões e já realizaram estudo de alternativas locacionais para instalação de aterro sanitário), 11 no Grupo C (municípios que destinam os resíduos sólidos em lixões e já obtiveram Licença de Prévia para instalação de aterro sanitário), 25 no Grupo D (municípios que destinam os resíduos sólidos em lixões e já obtiveram Licença de Instalação para aterro sanitário) e 20 no Grupo E (: municípios que destinam os resíduos sólidos urbanos em aterros que possuem ou já possuíram Licença de Operação). A Figura 1 ilustra o diagnóstico dos 141 municípios do Estado.

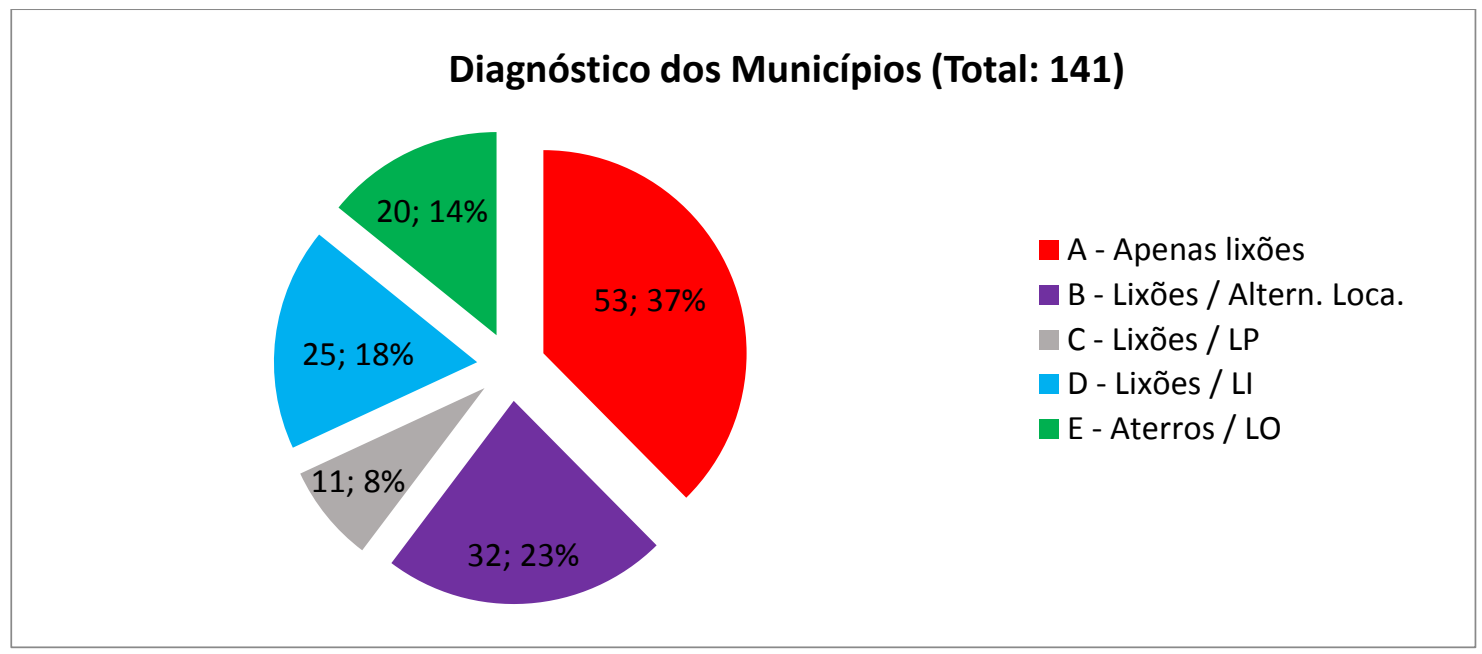

Figura 1 - Resultado do diagnóstico global dos municípios.

\subsection{Análise do Grupo A}

A análise do Grupo A aponta para a quantidade de municípios em inércia - que nunca iniciaram a regularização de um local apropriado para a destinação dos resíduos sólidos urbanos municipais. A Figura 4 ilustra a análise dos municípios que fazem parte do Grupo A, frente ao total de municípios do Estado, que representa $38 \%$ do total. 

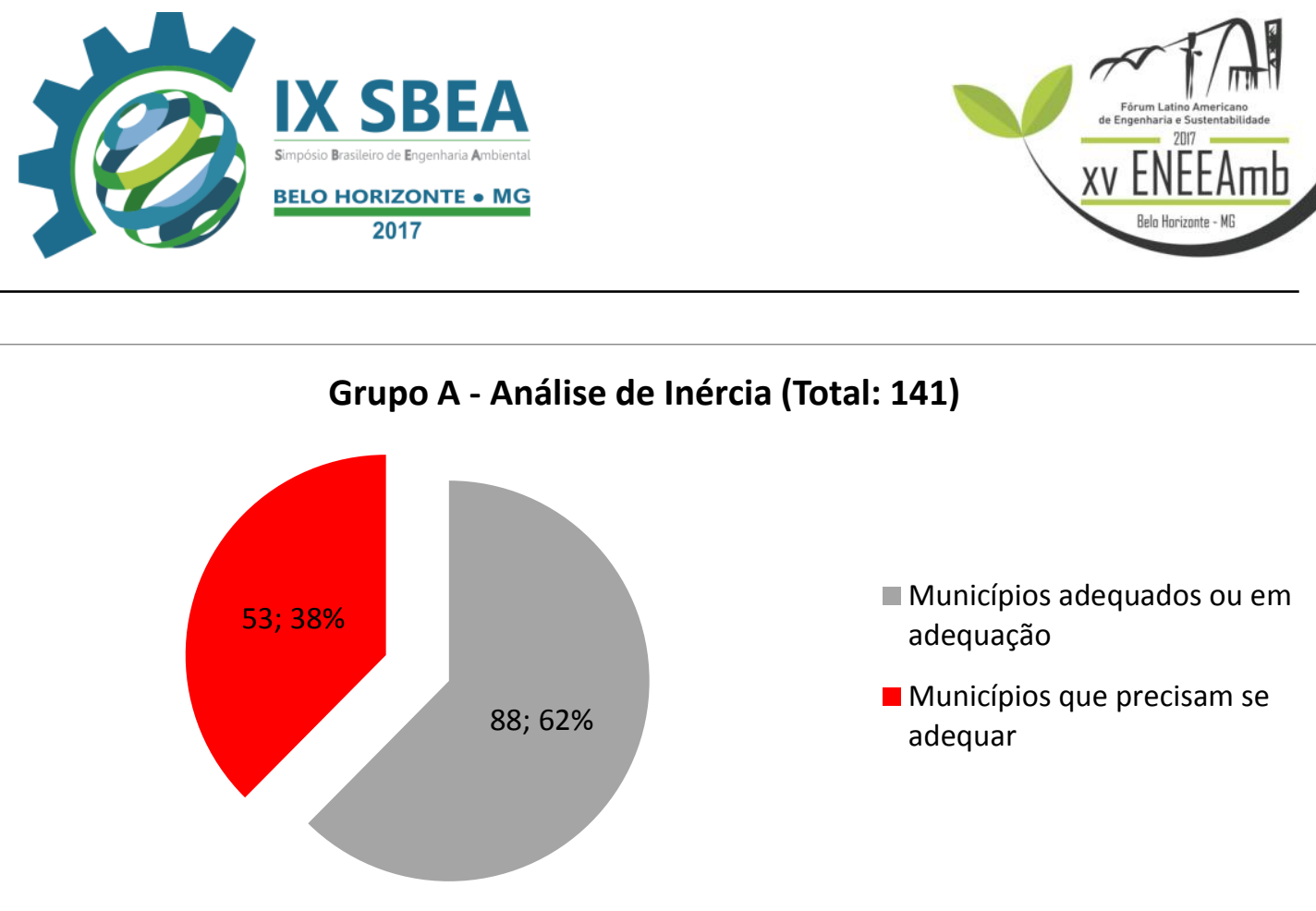

Figura 2 - Análise do Grupo A.

Compõem o Grupo A os seguintes municípios, ordenados em ordem alfabética na Tabela 2.

Tabela 2 - Municípios pertencentes ao Grupo A.

\begin{tabular}{ccc}
\hline & Municípios do Grupo A & \\
\hline Carlinda & $\begin{array}{c}\text { Nossa Senhora do } \\
\text { Livramento }\end{array}$ & Planalto da Serra \\
Castanheira & Nova Bandeirantes & Pontal do Araguaia \\
Colniza & Nova Brasilândia & Ponte Branca \\
Comodoro & Nova Guarita & Porto Alegre do Norte \\
Confresa & Nova Lacerda & Porto dos Gaúchos \\
Conquista d'Oeste & Nova Monte Verde & Porto Estrela \\
\hline Dom Aquino & Nova Nazaré & Poxoréu \\
\hline Figueirópolis d'Oeste & Nova Santa Helena & Querência \\
\hline Gaúcha do Norte & Nova Ubiratã & Reserva do Cabaçal \\
General Carneiro & Nova Xavantina & São José do Rio Claro \\
Guiratinga & Novo Horizonte do Norte & São José do Xingu \\
Itanhangá & Novo Mundo & São Pedro da Cipa \\
Itaúba & Novo Santo Antônio & Tabaporã \\
Jangada & Novo São Joaquim & Terra Nova do Norte \\
Juara & Paranaíta & Tesouro \\
Juruena & Paranatinga & União do Sul \\
\hline
\end{tabular}



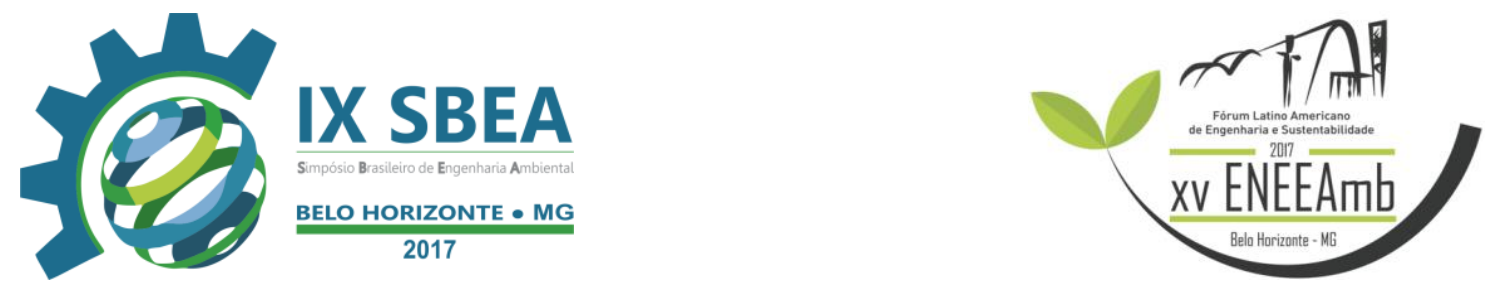

Juscimeira

Pedra Preta

Vila Bela da Santíssima Trindade

\section{Lambari d'Oeste}

Peixoto de Azevedo

\subsection{Análise do Grupo B}

Os municípios do Grupo B são apresentados na Figura 3 divididos por ano de realização dos Estudos de Alternativas Locacionais. Percebe-se que a maioria dos municípios realizaram os estudos e não deram continuidade no processo de regularização de aterros sanitários.

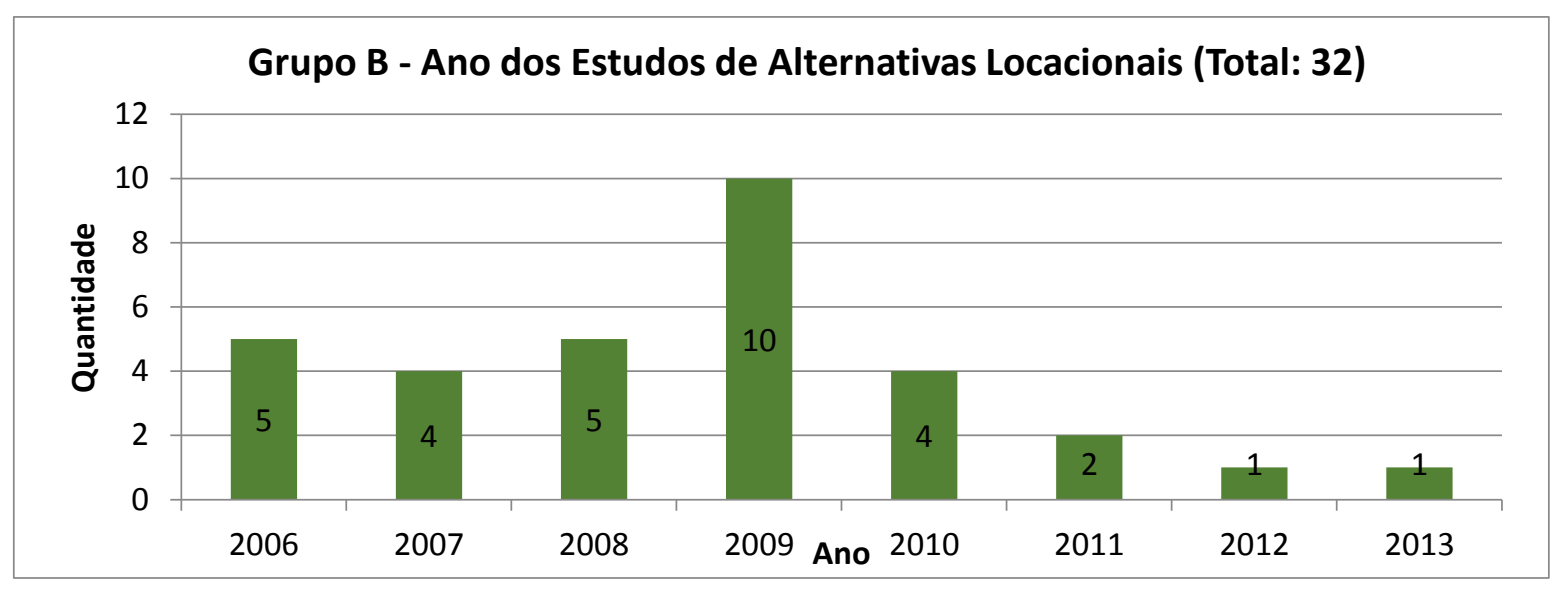

Figura 3 - Análise do Grupo B.

Compõem o Grupo B os seguintes municípios, ordenados em ordem alfabética na Tabela 3. Destaca-se também o ano de realização dos estudos.

Tabela 3 - Municípios pertencentes ao Grupo B.

\section{Municípios do Grupo B}

Acorizal (2009) Campinápolis (2009) Santa Rita do Trivelato

Alto Boa Vista (2006) Campos de Júlio (2009) Santa Terezinha (2007)

Alto Paraguai (2009) Canabrava do Norte (2009) $\quad$ Santo Antônio do Leste
Apiacás (2010)
Cláudia (2008)
Sto. Antônio do Leverger (2009)

Araguaiana (2008)

Cocalinho (2008)

São Félix do Araguaia (2006)

Araguainha (2007)

Luciara (2007)

São José do Povo (2006)

Aripuanã (2010)

Porto Esperidião (2013)

Serra Nova Dourada (2007)

Barão de Melgaço (2008)

Ribeirãozinho (2009)

Vale de São Domingos (2012) 

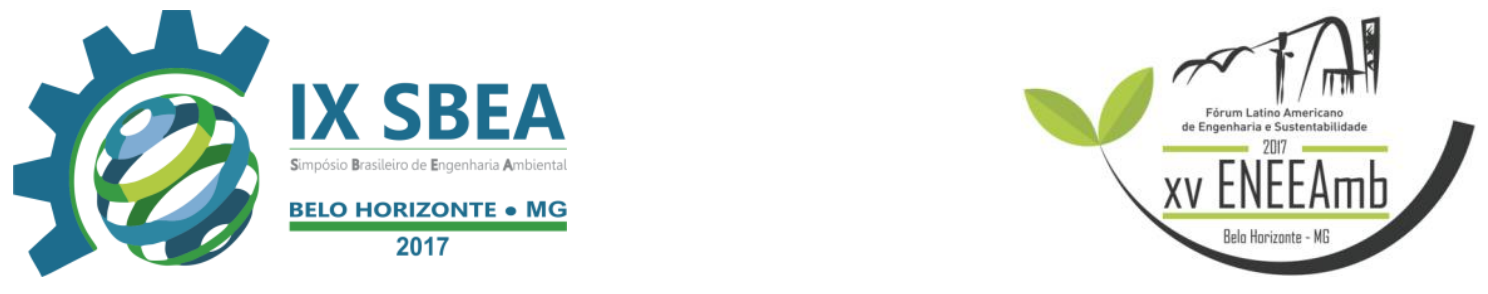

Barra do Bugres (2010)

Rondolândia (2008)

Várzea Grande (2006)

Bom Jesus do Araguaia (2011)

Salto do Céu (2006)

Vila Rica (2009)

Brasnorte (2011) Santa Cruz do Xingu (2010)

\subsection{Análise do Grupo C}

Os municípios do Grupo C foram são apresentados na Figura 4 divididos por ano de vencimento das Licenças Prévias. Percebe-se que a maioria dos municípios a obtiveram e não deram continuidade no processo de regularização de aterros sanitários.

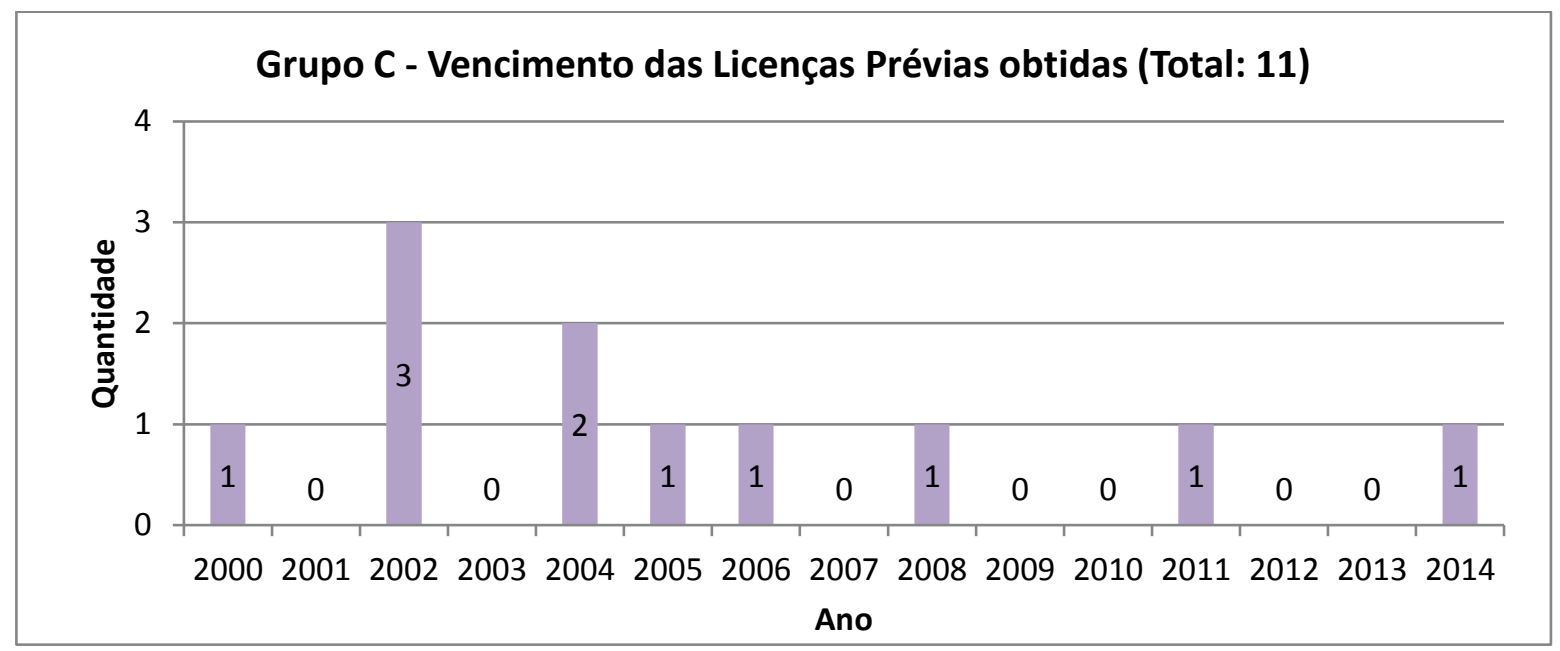

Figura 4 - Análise do Grupo C.

Compõem o Grupo $\mathrm{C}$ os seguintes municípios, ordenados em ordem alfabética na Tabela 4. Destaca-se também o ano de vencimento das LPs.

Tabela 4 - Municípios pertencentes ao Grupo C.

\section{Municípios do Grupo C}

Água Boa (2000)

Alto Araguaia (2005)

Alto Garças (2004)

Alto Taquari (2004)

Itiquira (2002)

Marcelândia (2002)

Poconé (2006)

Pontes e Lacerda (2002)

Primavera do Leste (2008) 

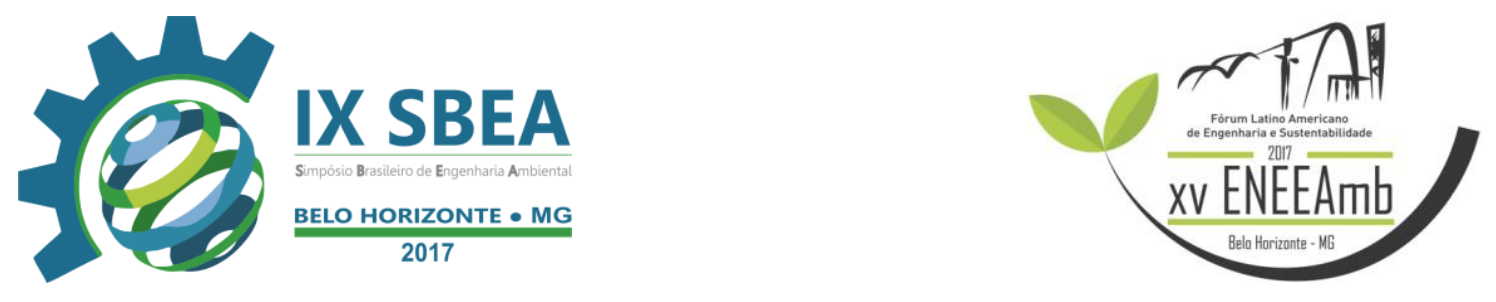

Rondonópolis (2014)

Sapezal (2011)

\subsection{Análise do Grupo D}

Os municípios do Grupo D foram são apresentados na Figura 5 divididos por ano de vencimento das Licenças de Instalação. A maioria dos municípios estão com as Licenças de Instalação com vencimento nos anos de 2013, 2014 e 2015. Este número representa a instalação de aterros sanitários em consórcios, atendendo vários municípios.

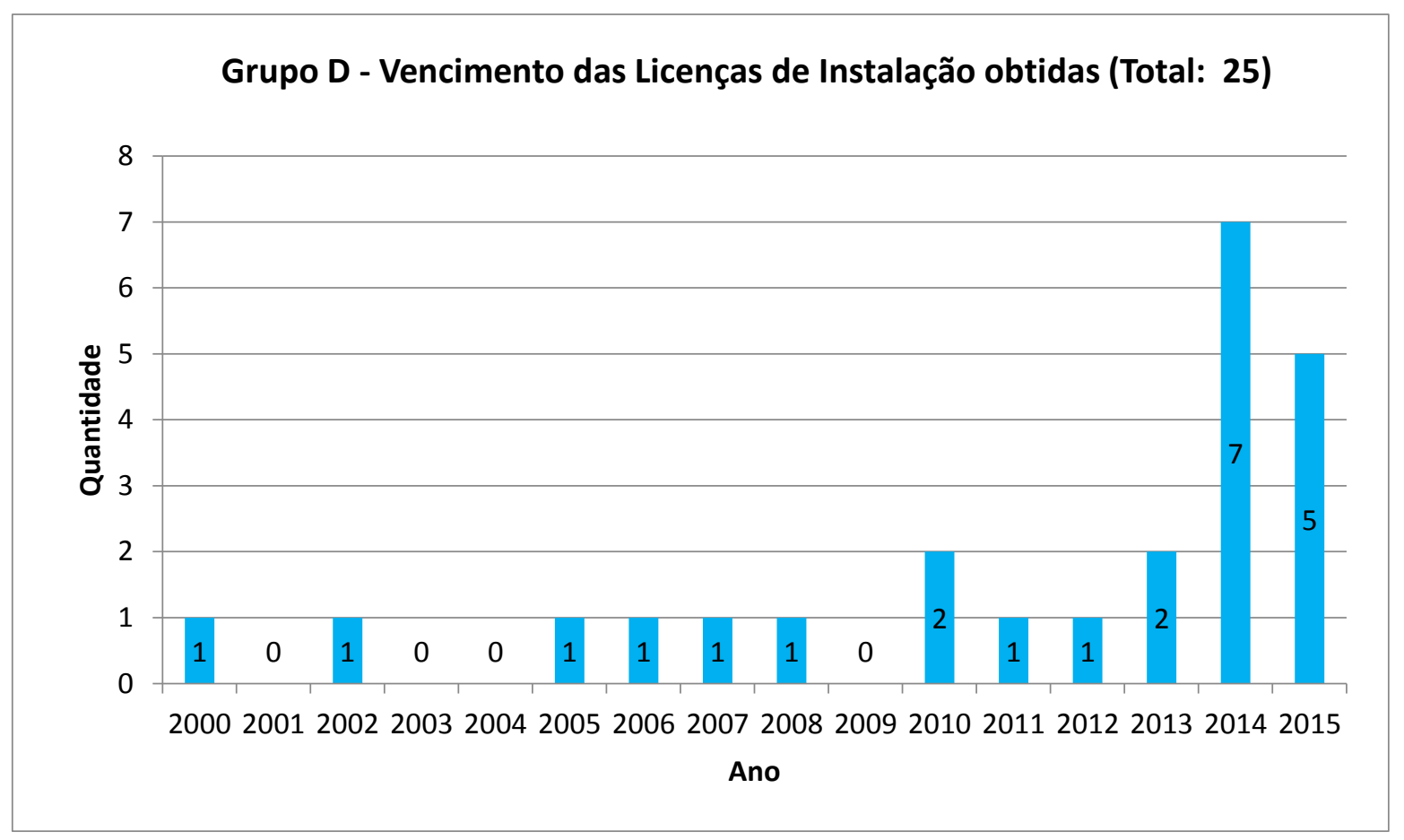

Figura 5 - Análise do Grupo D.

Compõem o Grupo D os seguintes municípios, ordenados em ordem alfabética na Tabela 6. Destaca-se também o ano de vencimento das LIs.

Tabela 5 - Municípios pertencentes ao Grupo D.

\section{Municípios do Grupo D}

Araputanga (2014)

Arenápolis (2015)

Cáceres (2011)

Campo Novo do Parecis (2010)

Canarana (2013)

Chapada dos Guimarães (2012)
Guarantã do Norte (2015)

Nova Olímpia (2000)

Indiavaí (2014)

Jaciara (2013)

Ribeirão Cascalheira (2008)

Rio Branco (2007)

Mirassol d'Oeste (2014)

Rosário Oeste (2002)

Nobres (2010)

Santa Carmem (2014)

Santo Afonso (2015) 

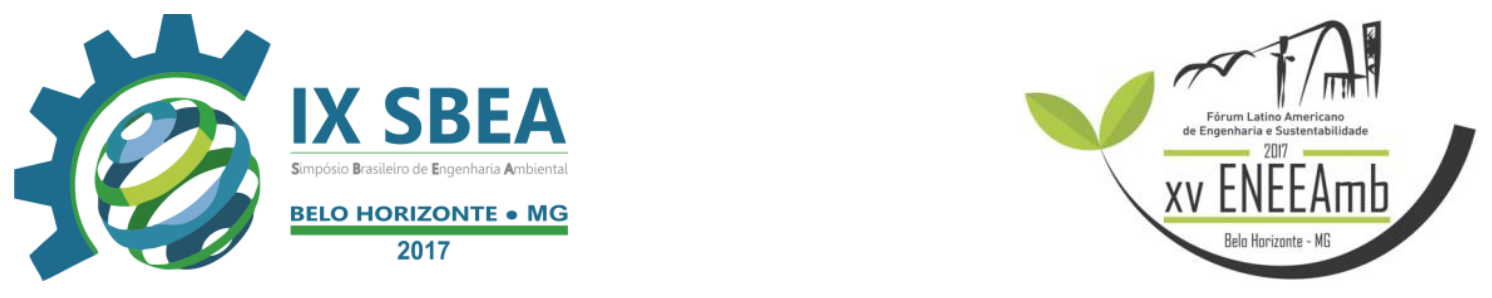

Curvelândia (2014) Nova Canaã do Norte (2016)

São José dos Quatro Marcos (2014)

Feliz Natal (2014) Nova Marilândia (2015)

Glória d'Oeste (2006) Nova Maringá (2005)

\subsection{Análise do Grupo E}

A análise do Grupo E foi dividida em duas etapas. A primeira etapa, Figura 6, apresenta a situação dos municípios que destinam em aterros que possuem ou possuíram Licença de Operação. Apesar de somarem vinte municípios, apenas dez estão em situação regular. Cinco municípios tiveram seus aterros sanitários transformados em lixões devido ao mau gerenciamento - tornando-se inviáveis as suas regularizações.

Cinco municípios apresentam-se parcialmente regulares. Dois não conseguiram renovar a Licença de Operação por possuírem aterros sanitários instalados em Área de Segurança Aeroportuária.

Os outros dois municípios em situação parcialmente regular representam: um município que possui aterro sanitário com Licença de Operação vencida desde 2012 e nunca destinou os resíduos sólidos urbanos ao aterro e um município que possui aterro sanitário com Licença de Operação vencida desde 2007 e está instalando novo aterro na mesma área, com Licença de Instalação com vencimento em 2015.

\section{Grupo E - Situação dos municípios que destinam em aterros que possuem ou possuíram Licença de Operação (Total: 20)}
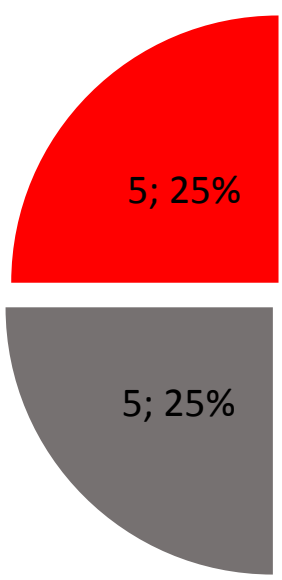

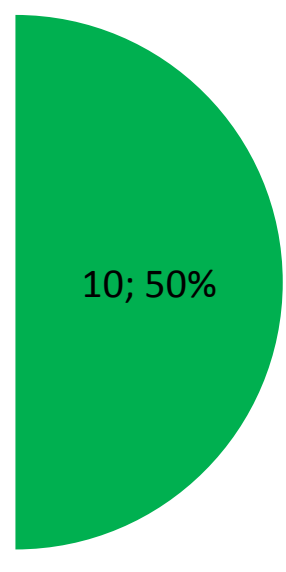

Regular

Parcialmente Regular

Irregular

Figura 6 - Análise I do Grupo E.

A segunda etapa da análise do Grupo E (Figura 7) apresenta que apesar de existirem nove municípios em situação regular, apenas quatro não possuem aterro sanitário licenciado e operado pelo município. Os outros cinco municípios possuem contrato com aterro sanitário privado para destinação dos resíduos sólidos urbanos. 

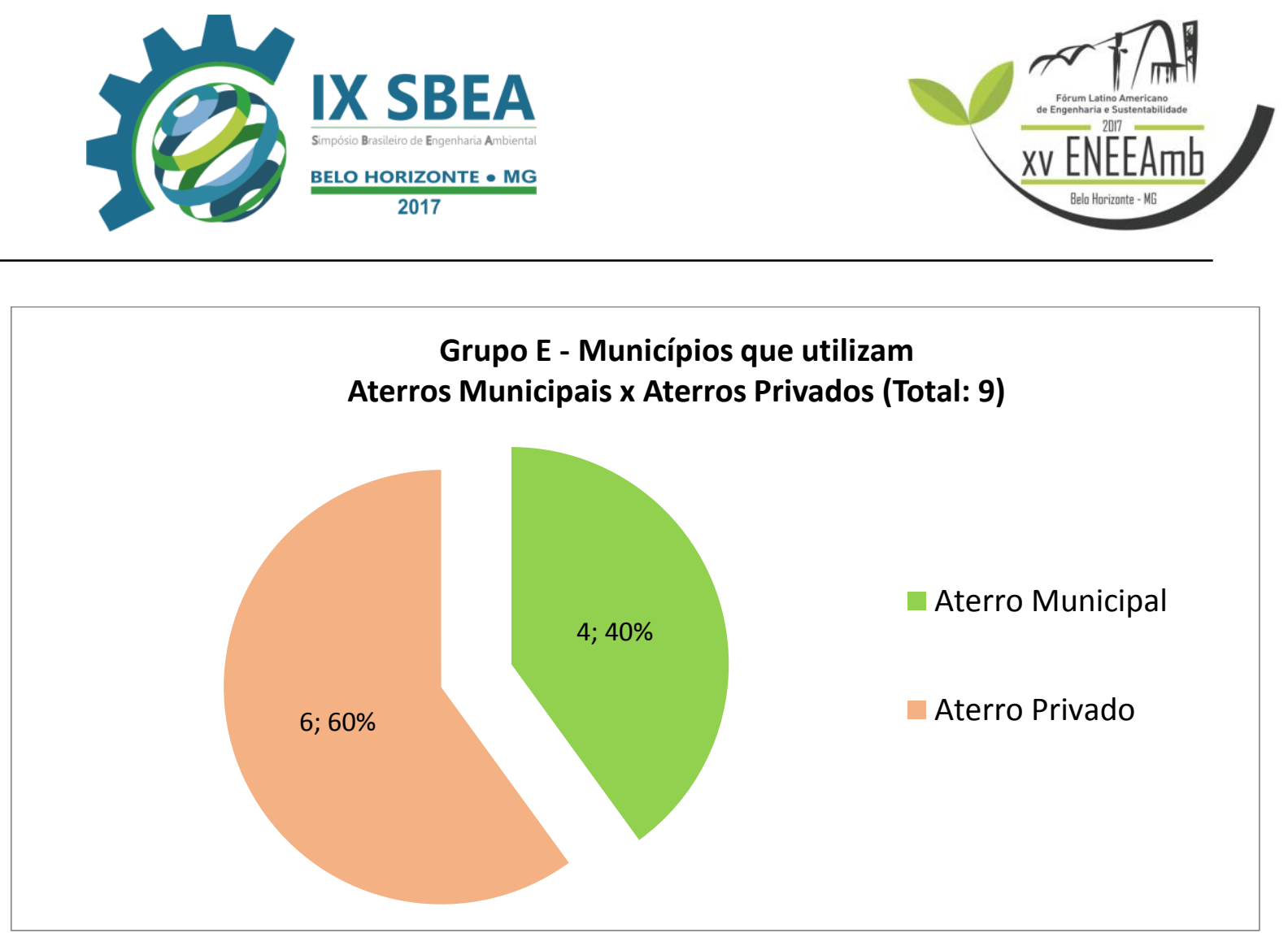

Figura 7 - Análise II do Grupo E.

Tabela 7.

Compõem o Grupo E os seguintes municípios, ordenados em ordem alfabética na

Tabela 6 - Municípios pertencentes ao Grupo E.

\begin{tabular}{ccc}
\hline & Municípios do Grupo E & \\
\hline Alta Floresta & Diamantino & Sinop \\
Barra do Garças & Ipiranga do Norte & Sorriso \\
Campo Verde & Jauru & Tangará da Serra \\
Colíder & Juína & Tapurah \\
Cotriguaçu & Lucas do Rio Verde & Torixoréu \\
Cuiabá & Matupá & Vera \\
\hline Denise & Nova Mutum & \\
\hline
\end{tabular}

Estão em situação regular os seguintes municípios de Colíder com LO válida até 2015, Cotriguaçu com LO válida até 2015, Cuiabá com LO para área emergencial obtida após assinatura de Termo de Ajustamento de Conduta para realização de estudos e instalação de aterro sanitário em nova área e Juína com LO válida até 2014.

Os municípios de Ipiranga do Norte, Lucas do Rio Verde, Nova Mutum, Sorriso, Tapurah e Vera destinam os resíduos para um aterro particular instalado em Sorriso, com LO válida até 2016.

O município de Alta Floresta opera por meio de concessão a empresa privada o antigo aterro sanitário e está instalando um novo em local anexo. Campo Verde possui aterro sanitário com LO vencida desde 2012 e nunca destinou resíduos ao mesmo. Matupá e Tangará da Serra possuem aterros sanitários em boas condições de operação e suas Licenças de Operação não foram renovadas devido os mesmos estarem inseridos na Área de Segurança 

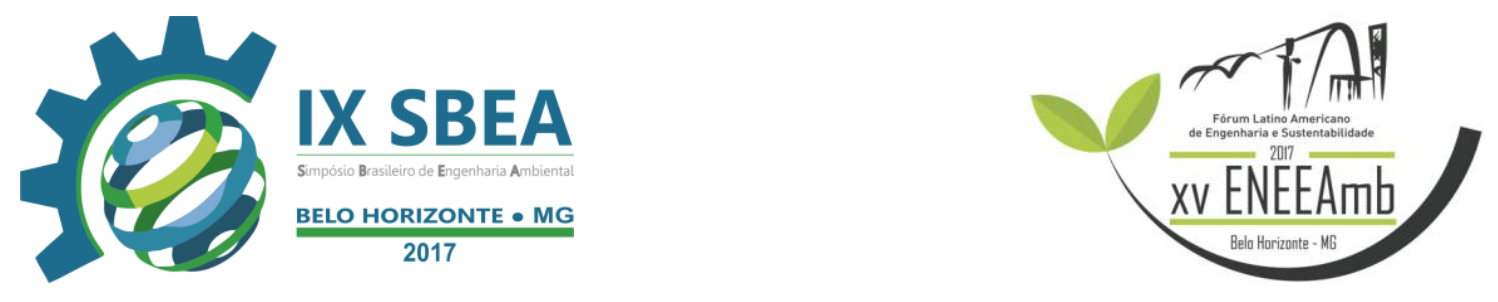

Aeroportuária de Aeroportos não homologados pela Agência Nacional de Aviação Civil. Torixoréu está em processo de renovação da Licença de Operação.

Os municípios de Barra do Garças, Denise, Diamantino, Jauru e Sinop tiveram os aterros sanitários transformados em lixões.

\section{CONCLUSÕES/RECOMENDAÇÕES}

O presente trabalho apresentou um panorama dos municípios do Estado de Mato Grosso quanto à existência de aterros sanitários licenciados. O Diagnóstico da situação dos municípios de Mato Grosso apresentou que apenas 20 municípios no estado possuem ou possuíram aterros sanitários com Licença de Operação, o que representa apenas $14 \%$ de um total de 141 municípios. Entretanto, destes vinte municípios, apenas dez encontram-se em situação regular.

Observou-se que uma grande parcela dos municípios, 53,38\% do total de municípios, se encontram em estado de inércia, ou seja, nunca iniciaram a regularização de um local apropriado para a destinação dos resíduos sólidos urbanos municipais. Outro ponto a ser destacado é que municípios do Grupo B e C iniciaram a regularização dos aterros sanitários, porém não deram prosseguimento ao processo.

Portanto, este estudo mostra que é necessário um melhor gerenciamento dos resíduos sólidos do Estado bem como o correto cumprimento dos critérios do licenciamento ambiental dos aterros sanitários.

\section{REFERÊNCIAS BIBLIOGRÁFICAS}

Brasil. 2010. Lei no 12305 de 2 de agosto de 2010. Institui a Política Nacional de Resíduos Sólidos no Brasil. Diário Oficial da União, Brasília-DF, 02 de agosto de 2010.

SEMA/MT. Secretaria de Estado do Meio Ambiente. www.sema.mt.gov.br. Acesso em julho/2013.

CONSELHO NACIONAL DO MEIO AMBIENTE. Resolução N. ${ }^{\circ}$ 04, de 09 de outubro de 1995. Estabelece as Áreas de Segurança Aeroportuária - ASAs. Diário Oficial da República Federativa do Brasil, 11 dez. 1995.

IBGE - Instituto Brasileiro de Geografia e Estatística - Disponível em: (www.ibge.gov.br) Acesso em: 22 de março 2017.

MUÑOS, S. I. S. Impacto ambiental na área do aterro sanitário e incinerador de resíduos sólidos de Ribeirão Preto, SP: Avaliação dos níveis de metais pesados. 2002. Tese (Doutorado em Saúde Ambiental) - Escola de Enfermagem, Universidade de São Paulo, Ribeirão Preto,2002. 